\title{
CONTEMPORARY ENDODONTIC OBTURATION TECHNIQUES: A COMPREHENSIVE LITERATURE REVIEW
}

\begin{abstract}
The success of an endodontic treatment is excessively depends on obturation as well as chemomechanical shaping. Hence, achiving a homogenious, impermeable and gap-free obturation plays a crucial role in endodontic treatment success. Today, many materials and techniques have been developed for endodontic purpose such as those which applied with heat or vibration, those softened with non-toxic chemicals and those uses ultrasound energy. Some of these techniques are still preferred by proffessionals when some are abandoned. However, gutta-percha is the most used material either with or without sealer. Gutta-percha can be applied with cold or warm techniques. It's known that warm gutta-percha technique leads a more homogenious obturation than cold techniques. Nevertheless, different obturation methods are convenient for different anatomic variations of root canal system. This review article summerize the contemporary and conventional obturation techniques with evaluation of their current status in endodontic implementation.
\end{abstract}

Keywords: Endodontic Obturation Techniques, Contemporary Obturation Techniques, Cold Gutta-Percha Techniques, Softened Gutta-Percha Techniques, Endodontic Treatment.
*Recai Zan ${ }^{1}$

Arzu Seyma Demir ${ }^{2}$

ORCID IDs of the authors:

R.Z. 0000-0002-2781-355X

A.Ş.D. $\quad 0000-0002-9095-2165$

1 Department of Endodontics, Faculty of Dentistry, Sivas Cumhuriyet University, Sivas, Turkey.

2 Intern Dt., Faculty of Dentistry, Sivas Cumhuriyet University, Sivas, Turkey.

Accepted : 07.09.2021

How to Cite: Zan R, Demir AŞ. Contemporary Endodontic Obturation Techniques: A Comprehensive Literature Review. Cumhuriyet Dent J 2021;24:3:310-317. 


\section{INTRODUCTION}

A total root canal obturation is a major objective in endodontic treatment procedures. ${ }^{1-3}$ The primary purpose of root canal obturations is preventing the microleakage and bacterial invasion between root canals and periradiculer tissues. Composing a both apically and coronally, three dimentional sealing is crucial in order to ensure maximum preservation of root canals from microorganisms and inhibit their penetration to periradicular tissues. ${ }^{4,5}$ Unsuccessful obturations that caused by necrotic debris, bacteria, bacterial toxins and pulp residues left in root canals can cause periradicular diseases and bacterial growth. ${ }^{2,6}$ It has been reported that insufficent endodontic obturations can cause unexpected postoperative complications in endodontic approaches with $65 \%$ rate. $^{2}$ There have been advancements in endodontic materials, equipments and techniques over the past two decades as we increased our knowledge about the nature of endodontics, endodontic diseases and the definition of endodontic success and failure. ${ }^{2,4,5,7}$ The standard obturation materials consist sealers and a solid core material placed in the center of the root canal space. ${ }^{6}$ Necessities of an obturation material have been explained in previous studies. ${ }^{3,6}$ The ideal obturation material should be biocompatible, anatomically compatible, well adapted to the walls in three dimensions, cover the root canal spaces well apically and coronally, easily removed when needed and definable in radiographs. It also should have dimentional stability to prevent irregularities., ${ }^{3,6}$ Thus, gutta-percha has been the most preferred obturation material due to its useful properties but most of the cases, the root canal spaces do not be completely filled with the obturation materials and that causes problems. ${ }^{3,6,8}$ For many years, gutta percha was the priory option for a gap free and homogeneous fillings both in the apical, middle and coronal third of root canals. ${ }^{8}$ However, different obturation materials and systems have been developed and used over the years for a better endodontic treatment. ${ }^{3}$ The aim of this review is investigating the contemporary root canal obturation techniques in endodontics.

\section{1) Cold Gutta-Percha Techniques}

\section{A. Single Gutta Percha Technique:}

In this technique, the obturation made by single cone which is master cone and do not necessity of the use of accessory cones. Single gutta percha technique shows exceptional adaptation to the root canals especially when the root canals expanded with rotary nickel-titanium systems. Because master cone can match the geometry of last rotary instruments used and provide a void free, nonpermeable filling as it prevents the leakage between apical of roots and the periradicular tissues. ${ }^{5}$ Using of single gutta percha technique has increased recently and the number one reason to prefer this method is the time advantage and simplicity of the technique. ${ }^{9,10}$ Chybowski et al. reported the clinical success of single cone technique used with bioseramic sealer. The useful qualties of bioseramic sealers and its compatibility with single cone technique have influenced the success by causing an advanced sealing in the root canals of the teeth. This technique also provided a more conservative preperation rather than traditional warm lateral and vertical compaction techniques. ${ }^{11}$ It's been also proven in a study, warm lateral condansation and vertical compaction techniques are disadvantageous due to their nonhomogenity and poor adaptation characteristics. ${ }^{12}$ In a study that made with two groups of maxillary and mandibulary canines with single straight canals, using single cone technique with RoekoRSA sealing in one year follow-up study on leakage that demonstrated by Wu et al. as there was no leakage after 1 year of the treatment. Because of the RSA sealer was insoluable, it showed a promising result when used with single cone technique. $^{13}$

Altough single cone with a sealer technique has an important advantages as it fits precisely and composes a gap free filling in root canals that has shaped with a rotary instruments, there's disadvantages of this method such as the single cone is not compatible with the irregularities in the middle and coronal $1 / 3$ of the canal. Thus, if these areas filled only with sealer; occured gaps can damage the mass integrity in terms of the long term success of the endodontic treatment. Another fact about the single cone technique is the cytotoxicity 
of solvents. Morover, gutta percha shows dimensional changes when the solvent dries. Besides, single cone technique has the risk of flooding and disjunction because of the chemical features of gutta percha. ${ }^{9}$

\section{B. Lateral Compaction Technique:}

Lateral condensation technique is the most frequently used technique in endodontics. ${ }^{8,14,15}$ This technique based on a master apical cone sent to the full working length and accessory cones placed around the master gutta percha cone with sealer. Spreaders used for lateral compaction, sent to the 1-2 mm shorter than the working length until the spreader can not move more than 1-2 $\mathrm{mm}$ in root canal opening. ${ }^{9,16}$ Lateral compaction technique offers a more controlled obturation but disadvantageous for treatment time. In this method, gutta perchas poorly adopts the root canal walls and comprises inhomogenity. ${ }^{17}$ It's been reported in a study that compares sealing efficacy of 2 warm vertical compaction technique with single cone and lateral compaction technique, single cone and lateral compaction technique showed the lowest fluid permeability with a similar result. ${ }^{18}$ Besides, this technique offers a greater dimensional stability. ${ }^{1}$ Also, lateral compaction technique has been accepted and applied succesfully by dentists for years due to its easiness of controlling and favorable characteristic of providing patients comfort. ${ }^{1}$ However, it has been reported that the new core carrier systems are more promising than traditional lateral condensation and single cone techniques in the manner of void-free filling in root canal systems. ${ }^{19}$

\section{Softened Gutta-Percha Techniques}

\section{A. Heat-Softened Gutta-Percha Techniques B. Warm Lateral Compaction Technique:}

Cold lateral condansation technique is the most widely used technique in endodontics, besides the favorouble features of this technique. Its important disadvantages are homogenity of the mass of gutta percha and poor adaptation to root canal walls and irregularities of root canal system..$^{20,21}$ Thus, a better and advanced technique started to be applied. ${ }^{20}$ Warm lateral compaction technique requires a peizoelectric ultrasonic unit, a file adaptor and a $\mathrm{K}$ type of file. ${ }^{21}$ With warm lateral compaction technique, the disadvantages of cold lateral compaction technique were eliminated as well as it provides a more homogen filling with less voids in the root canal system. ${ }^{20}$ This technique also favorable in the manner of filling accessory and lateral canals also considered as a cost effective. $^{21}$ Clinton and Himmel compared the adaptation of two different obturation techniques as lateral condansation and warm gutta percha obturation techniques on root canal walls. They conducted that warm gutta percha technique showed a better adaptation in root canal system and left less voids than the lateral condansation technique because of the flowing features of warm methods. ${ }^{8}$ A similar another study conducted 60 extracted teeth with lateral canals, divided 6 groups and used different obturation techniques that divided into 2 subgroups for the rank of filled lateral canals, Goldberg reported that the difference between 2 subgroups was significant and the teeth obturated with Ultrafil succesfully filled the lateral canals. ${ }^{22}$ Morover, Kersten compared several obturation techniques such as cold lateral compaction, thermoplasticized gutta percha and thermomecanical compaction. He reported that warm lateral compaction technique caused minimum leakage in the apical of the root canals. ${ }^{23}$ Nelson et $a .^{24}$ compared cold and warm lateral compaction techniques and reported that warm lateral compaction method showed a significantly higher density because of the application of the heat. Furthermore, System B instrumentation were used in low heat lateral condensation technique. ${ }^{24}$ Nevertheless, warm lateral compaction technique is more advantageous than standard lateral compaction technique in many aspects. ${ }^{24}$

\section{i) Warm Vertical Compaction Technique:}

This technique also know as Schilder technique as it introduced by Schilder for the first time in 1967. ${ }^{21}$ It's also knows as wave compaction technique. ${ }^{24}$ The purpose of this technique is to provide an enhanced plugging especially in complicated root canal systems by filling accessory and lateral canals and internal resorption defects. ${ }^{9,21}$ Heat systems and pluggers required for this technique. ${ }^{21}$ The technique starts with sealing the root canals with a sealer and placing the master gutta-percha cone. The heated 
gutta-percha cones should be added to canals by condencing vertically with spreader until ensuring a hermetic filling. ${ }^{9}$ According to Kececi et al., contunious wave obturation technique was more favorable than lateral condansation technique in terms of treatment time. Wave obturation technique was choosen in that study because of its advantageous features such as minimal apical leakage and its duration. ${ }^{16}$ Also, vertical compaction with warm gutta-percha presents the most frequent filling in lateral canals and foramina among other techniques. ${ }^{1}$ Interestingly, in a study demonstrated by Aminsobhani et. al., 3 obturation techniques that are lateral compaction, warm vertical compaction and Guttaflow System were compared by their permeability to saliva and their coronal microbial leakage and resultly no significant difference was found in 3 techniques. ${ }^{25}$ However, warm vertical compaction technique has a few disadvantages such as the high cost of the equipment and the difficulties of length control. ${ }^{21}$ On the other hand, this technique is preferable because it decreases apical leakage and provides a dense filling in root canal systems. ${ }^{9,21}$ Venturi conducted that, vertical compaction technique was more successfull in creating a three dimentional homogenious filling when it's applied with apical backfilling method. ${ }^{26}$

\section{Thermomechanical Compaction Technique:}

Thermomechanical compaction technique was founded by Mc Spadden and developed by Tagger et al. This technique is based on heating the guttaperchas and thermoplastised them by thermomechanical compactors. ${ }^{27}$ The heat occurs when an inverted Hedstrom file driven into the gutta-percha with slow handpieces. ${ }^{21}$ The application of this technique should be as pressuring apically, lateraly and coronally in the root canals. ${ }^{21,27}$ Plasticized gutta-perchas performs an enhanced homogenity and adaptation in root canals. Thus, this technique is advantageous and preferred by dentists especially difficult root canal shapes. ${ }^{28}$ Also it's preferable because of the easiness to apply and good filling quality in canal irregularities. $^{29}$ However, thermomechanical compaction technique allows more leakage than HeroFill Soft-Core technique but less than lateral compaction method according to Boussetta et al. ${ }^{30}$
It also has some disadvantages such as contraindication of narrow root canals because of the risk of the breakage of compactor and vertical root fractures. ${ }^{9}$ According to a study, if different gutta-percha materials compared in the canals that obturated with thermomechanical obturation technique, Resilon gives better results in the percentance of lateral canal filling. Also, the rates were higher especially in the middle and apical areas. ${ }^{27}$ It's notable that hybrid thermomechanical compaction technique causes less bond strength than lateral compaction technique. ${ }^{31}$ Also, the higher bond strength to dentine in the root was the combination of AH Plus/GP in the canals obturated with lateral compaction technique. ${ }^{31}$ There are many modifications of thermomechanical compaction technique such as Tagger technique. In Tagger technique, cold lateral condensation applied before inverting reverse Hedstrom file differently than the original technique. Another modification is Microseal that the flowable gutta-percha covered condensers used. ${ }^{21}$

\section{Thermoplasticized Gutta-Percha Enjection:}

In this technique, gutta-percha materials plasticized with heat and applied in the mechanically prepared root canals with pressure. ${ }^{9}$ De-Deus et al. $^{32}$ reported that, thermoplastized obturation techniques caused higher results than lateral compaction technique in the percentance of gutta-percha filled area in oval shaped canals. Gulabivala et al. ${ }^{33}$ reported that thermoplasticized gutta-percha techniques may be disadvantageous due to unpredictibility obturating length and they offered to fill the apical area of root with a controlled technique such as lateral condansation technique.

\section{a. Obtura 3 Max}

Obtura 3 Max system is the most recent example in thermoplasticized gutta-percha technique. ${ }^{9}$ This sytem comprise a needle with a slicone stop and a gun that can be controllable., ${ }^{921}$ It's a high working temperature device and it can heat the gutta-percha cones up to 160 degree. ${ }^{9}$ Obtura 3 Max system is favorable due its well adaptation to root canal walls. ${ }^{34}$ 


\section{b. Ultrafil 3D}

This system consists of a low working temperature $\left(70{ }^{\circ} \mathrm{C}\right)$ device and 3 different disposable needles for different canal shapes. ${ }^{29}$ The device is portable and nonreactive to moist or heat. It's notable that the low expanding percentance results a better sealing in the root canal system. ${ }^{35}$ This injection should be made slowly and under control. It's also important to not pressure to needle to prevent possible gaps in the root canals. ${ }^{9}$

\section{E. Trifecta:}

This technique considered as a safer technique with a gutta-percha barrier in the apical $2 \mathrm{~mm}$ area and filling the middle and apical areas with thermoplasticized injection. The gutta-percha barrier prevents the flowing of gutta-percha from apical of the root canals. ${ }^{9}$ Al-Dewani et al. compared the seability and radiographic quality of two different obturation techniques that are lateral condansation and Trifecta system. The study was made on one hundred human teeth with single root. They reported that, Trifecta showed an enhanced seability and less apical dye penetration than lateral condensation technique but it demonstrated poorer radiographic quality. They also concluded that Trifecta is a good alternative to lateral condansation technique. ${ }^{36}$ It's worth to say that as thermoplasticized obturation techniques gives a better adaptation on root canal walls, it's necessery to use sealers for an enhanced seal. ${ }^{36}$

\section{F. Thermafill:}

Thermafill is a carrier based technique includes a gutta-percha coated with carrier. A gutta-percha coated core material used as a carrier and applied in the root canals after heated in special ovens. The use of sealer are necessery in Thermafill technique. Grossman formulated $\mathrm{AH} 26$ and $\mathrm{AH}$ plus sealers are suggested for this technique but TubliSeal and Watch's sealers are not recommended. ${ }^{14}$ The heated carrier should be sent to the sealed and biomechanically prepared root canals. It's important to remove smear layer with the preparation and before filling the root canal system. ${ }^{14}$ This technique is favorable because of time efficiency, its easily removable and impermeable nature. ${ }^{9,14,21}$ Gutta-percha succesfully fill the lateral and accessory canals with this technique. ${ }^{14}$ Hovewer, the risks of this technique are the possibility of post operative pain and diffuculties of length control. ${ }^{21}$ Also, difficult retreatment prosedure and the risk of core material to get out of gutta-percha harden the endodontic treatment process. ${ }^{14}$ There are several carriers as Protaper, Recripoc, Waveone, GuttaCore etc., ${ }^{9,21}$

\section{G. Soft-Core:}

This technique is similar to Thermafill. The heated carriers sent to the working lenght in the root canals. Differently than Thermafill, Soft Core consists of 2 sections which are metal prob and plastic gutta-percha cone. The metal pin does not hold the plastic core completely, and after the soft core is placed in the groove, the plastic handle is bent and removed together with the metal pin. ${ }^{6}$

\section{H. Alpha-Seal:}

Although the system is basically similar to the Thermafill, the different carrier part of the system which is the alpha seal gutta percha is adapted to the $\mathrm{K}$ type file by the dentist. In Alpha-Seal technique a sterile file that is the same size as the master apical file is used with a warmed alpha seal syringe inserted into it. After that, when the syringe removed, the gutta percha is covered around the file and can be placed in the root canals. Also, gutta-perchas heated for decreasing the moleculer weight in this technique. AlphaSeal technique advantageous because its avaible for trying in root canals and making the corrections during treatment. ${ }^{6}$ In a study made by Gulabivala et al., thermoplasticized gutta-percha obturation techniques was compared with cold lateral condansation technique. Alpha-Seal had more overfills than Quick Fill and more extrusion of gutta-percha than lateral condensation and Thermafill. They also concluded that the thermoplasticized gutta-percha techniques were more time-efficent than lateral condensation technique. ${ }^{33}$

\section{İ. SuccessFil:}

SuccessFil is also a carrier based obturation technique. Carriers are placed in syringe that measure the root canal lenght. After applying sealer to the root canals, gutta percha carrier send to the canal lenght. Morover, pluggers that chosen 
according to canal morphology can be used in this technique. ${ }^{14}$ Goldberg et al. compared three different obturation techniques which are Trifecte, lateral condansation and combination of lateral condansation and SuccessFil. They demonstrated that if lateral condansation technique applied with successfil showed better results as enhanced adaptation to root canal walls and condensed filling. ${ }^{37}$

\section{J. System B}

System B is a heating system that uses with two special technics called down pack and backfilling technique. ${ }^{21}$ In down pack technique, a thin layer of sealer should be applied in the walls of the canals, after applying sealer, master cone should be placed and heated with a System B heat source and bind with a System B plugger gently then switch to Machtou plugger until create a hermetic, homogen filling. ${ }^{9,21}$ In backfilling technique a selected needle used to plasticized gutta-percha and fill the canals. Before canal opening, draw back the needle and use pluggers for pressure. ${ }^{21}$ Lea et al. evaluated the obturation density in two control groups, comparing cold lateral and warm vertical condansation techniques with System B, conducted that warm vertical compaction technique showed significantly higher density. ${ }^{17}$ Inan et. al. conducted that System B caused less leakage than Thermafill technique. ${ }^{38}$ In another study the sealing ability of two different obturation methods were compared, cold lateral compaction and system B, it has been concluded that System B showed significantly more sealing than cold lateral technique and cold lateral technique showed significantly more apical leakage. ${ }^{39}$ Calamus and Elements are other systems similar with System B. Both techniques have a gun system. ${ }^{9}$ In these systems, guttaperchas are heated before sending to canals up to $200 .^{40}$

\section{Other Techniques}

\section{A. Ultrasound Technique}

Ultrasound is an energy of sound with over 20 $\mathrm{kHz}$ frequence which is higher than sensible frequency for human. It was used for cavity preparation in dentistry under minimal invasive techniques. ${ }^{41}$ This technique was first introduced in endodontics by Richman and developed by Howard Martin. ${ }^{42}$ Ultrasound technique might be very benefical in terms of cleaning the debriment in the root canal system. Also it has following features such as easiness to access of root canal orifice, better preparation and enhanced extirpation of root canals. Morover, ultrasound irrigation was founded more effective than passive irrigation. ${ }^{41}$ It was reported by Townsend that ultrasonic irrigation was more effective in removing microorganisms from root canal system in an in vitro study. ${ }^{43}$ It's also known that ultrasonic irrigation technique is more adventageous specially in curved and wide canals. It's been concluded that, ultrasonic irrigation in a combination with conventional irrigation can improve the success of endodontic treatment. ${ }^{41}$ Nevertheless, ultrasound technique provides a preferable irrigation, cavity cleaning, removal of posts and broken instruments in the root canals. ${ }^{44}$

\section{CONCLUSIONS}

In endodontic evoluation, many obturation techniques have been applied and devoloped to create a homogeneous, void-free and impermeable filling. Nevertheless, gutta-percha cones are the most used material in endodontic treatment. Therefore, the root canal obturation techniques divided mainly two categories as cold and warm gutta-percha techniques. These techniques were developed due to spesific need in the treatment depending the various anatomic variations of the root canal systems. In this context, choosing the obturation technique that is suitable for the anatomic variations of the tooth in case is essential for determining the long term endodontic success. Also, using quality sealing material also plays a crucial role in the endodontic treatment. However, lateral condansation technique is the most preferred obturation technique that is widely accepted and suggested by clinicians in endodontics. In conclusion, it's known that modified contemporary obturation techniques are more efficient than the traditional techniques because of the following reasons; enhanced filling quality, minimum leakage percentances, more homogenious fillings and better obturation results in long term. Nevertheless, more compherensive 
studies and developments on current obturation techniques are needed to adjust the best quality of endodontic obturation and to obtain maximum performance with minimum disadvantages.

\section{REFERENCES}

1. Schilder H, Hargreaves KM. Filling root canals in three dimensions. J Endod. 2006;32(4):281-290.

2. Tabassum S, Khan FR. Failure of endodontic treatment: The usual suspects. Eur J Dent 2016;10:144147.

3. Hammad M, Qualtrough A, Silikas N. Evaluation of Root Canal Obturation: A Three-dimensional In Vitro Study. J Endod. 2009;35(4):541-544.

4. Sly MM, Moore BK, Platt JA, Brown CE. Push-Out Bond Strength of a New Endodontic Obturation System (Resilon/Epiphany). J Endod. 2007;33(2):160162.

5. Cardoso Pereira A, Kenji Nishiyama C, de Castro Pinto L, de Castro Pinto Rua Silvio Marchione L. Single-cone obturation technique: a literature review. RSBO Revista Sul-Brasileira de Odontologia 2012;9:442-447.

6. Haznedaroğlu F, Barut G, Armağan S, Kutlu Basmacı G. Kök kanalının doldurulmasında sıcak gütaperka teknikleri. Sazak Öveçoğlu H, editör. Kök Kanallarının Doldurulması. 1. Baskı. Ankara: Türkiye Klinikleri; 2019. p.25- 32.

7. Barnes JJ, Patel S. Contemporary endodontics-Part 1. Br Dent J. 2011;211(10):463-468.

8. Clinton K, Van Himel T. Comparison of a warm Gutta-percha obturation technique and lateral condensation. J Endod. 2001;27(11):692-695.

9. Kaplan T, Sönmez Kaplan S, Sazak Öveçoğlu H. Güncel kök kanal dolum teknikleri. Sazak Öveçoğlu H, editör. Kök Kanallarının Doldurulması. 1. Baskı. Ankara: Türkiye Klinikleri; 2019. p.18-24.

10. Eneas F, Figueiredo D De, Lima LF, Oliveira LS, Ribeiro MA, Correa MB, et al. Effectiveness of a reciprocating single file, single cone endodontic treatment approach: a randomized controlled pragmatic clinical trial. 2020;24:2247-2257.

11. Chybowski EA, Glickman GN, Patel Y, Fleury A, Solomon E, He J. Clinical Outcome of Non-Surgical Root Canal Treatment Using a Single-cone Technique with Endosequence Bioceramic Sealer: A Retrospective Analysis. J Endod. 2018;44(6):941-945. 12. Taşdemir T, Er K, Yildirim T, Buruk K, Çelik D,
Cora S, et al. Comparison of the sealing ability of three filling techniques in canals shaped with two different rotary systems: A bacterial leakage study. Oral Surgery, Oral Med Oral Pathol Oral Radiol Endodontology. 2009;108(3):e129-134.

13. Wu MK, van der Sluis LWM, Wesselink PR. A 1year follow-up study on leakage of single-cone fillings with RoekoRSA sealer. Oral Surgery, Oral Med Oral Pathol Oral Radiol Endodontology. 2006;101(5):662667.

14. Hargreaves, Kenneth M., Stephen Cohen, and Louis H. Berman. Cohen's pathways of the pulp. St. Louis, Mo: Mosby Elsevier. 2011:356-367.

15. Ordinola-Zapata R, Bramante CM, Graeff MSZ, del Carpio Perochena A, Vivan RR, Camargo EJ, et al. Depth and percentage of penetration of endodontic sealers into dentinal tubules after root canal obturation using a lateral compaction technique: A confocal laser scanning microscopy study. Oral Surgery, Oral Med Oral Pathol Oral Radiol Endodontology. 2009;108(3):450-457.

16. Keçeci AD, Çelik Ünal G, Şen BH. Comparison of cold lateral compaction and continuous wave of obturation techniques following manual or rotary instrumentation. Int Endod J. 2005;38(6):381-388.

17. Lea CS, Apicella MJ, Mines P, Yancich PP, Parker $\mathrm{MH}$. Comparison of the obturation density of cold lateral compaction versus warm vertical compaction using the continuous wave of condensation technique. J Endod. 2005;31(1):37-39.

18. Yilmaz Z, Deniz D, Ozcelik B, Sahin C, Cimilli H, Cehreli ZC, et al. Sealing efficiency of BeeFill 2in1 and System B/Obtura II versus single-cone and cold lateral compaction techniques. Oral Surgery, Oral Med Oral Pathol Oral Radiol Endodontology. 2009;108(6):e51-55.

19. Schäfer E, Schrenker C, Zupanc J, Bürklein S. Percentage of Gutta-percha Filled Areas in Canals Obturated with Cross-linked Gutta-percha Core-carrier Systems, Single-Cone and Lateral Compaction Technique. J Endod. 2016;42(2):294-298.

20. Luccy CT, Norman Weller R, Kulild JC. An evaluation of the apical seal produced by lateral and warm lateral condensation techniques. J Endod. 1990;16(4):170-172.

21. Tomson RME, Polycarpou N, Tomson PL. Contemporary obturation of the root canal system. Nat Publ Gr. 2014;216:315-322. 
22. Goldberg F. Effectiveness of different obturation techniques in the filling of simulated lateral canals. $\mathbf{J}$ Endod. 2001;27(5):362-364.

23. Kersten Hw, Fransman R, Velzen Skt. Thermomechanical compaction of gutta-percha. I. A comparison of several compaction procedures. Int Endod J. 1986;19(3):125-133.

24. Nelson EA, Liewehr FR, West LA. Increased density of gutta-percha using a controlled heat instrument with lateral condensation. $\mathrm{J}$ Endod. 2000;26(12):748-750.

25. Aminsobhani M, Ghorbanzadeh A, Bolhari B, Shokouhinejad N, Ghabraei S, Assadian H, et al. Coronal Microleakage in Root Canals Obturated with Lateral Compaction, Warm Vertical Compaction and Guttaflow System. Iranian Endodontic Journal. 2010;5:83-90

26. Venturi M. Evaluation of canal filling after using two warm vertical gutta-percha compaction techniques in vivo: A preliminary study. Int Endod J. 2006;39(7):538-546.

27. Sant'Anna-Júnior A, Tanomaru-Filho M, Hungaro Duarte MA, Santos Nunes Reis JM, GuerreiroTanomaru JM. Temperature Changes in Gutta-Percha and Resilon Cones Induced by a Thermomechanical Compaction Technique. J Endod. 2009;35(6):879-882.

28. De Gregorio C, Estevez R, Cisneros R, Paranjpe A, Cohenca N. Efficacy of different irrigation and activation systems on the penetration of sodium hypochlorite into simulated lateral canals and up to working length: An in vitro study. J Endod. 2010;36(7):1216-1221.

29. Lokhande PR, Deenadayalan, Ghorpade RR, Srinidhi SR. A review of contemporary research on root canal obturation and related quality assessment techniques. Springer Singapore; 2019;511-525.

30. Boussetta F, Bal S, Romeas A, Boivin G, Magloire $\mathrm{H}$, Farge $\mathrm{P}$. In vitro evaluation of apical microleakage following canal filling with a coated carrier system compared with lateral and thermomechanical guttapercha condensation techniques. Int Endod $\mathrm{J}$. 2003;36(5):367-371.

31. Carneiro SMBS, Sousa-Neto MD, Rached-Júnior FA, Miranda CES, Silva SRC, Silva-Sousa YTC. Pushout strength of root fillings with or without thermomechanical compaction. Int Endod J. 2012;45(9):821-828.

32. De-Deus G, Reis C, Beznos D, de Abranches
AMG, Coutinho-Filho T, Paciornik S. Limited Ability of Three Commonly Used Thermoplasticized GuttaPercha Techniques in Filling Oval-shaped Canals. J Endod. 2008;34(11):1401-1405.

33. Gulabivala K, Holt $\mathrm{R}$, Long $\mathrm{B}$. An in vitro comparison of thermoplasticised gutta-percha obturation techniques with cold lateral condensation. Endod Dent Traumatol. 1998;14(6):262-269.

34. Dabra A, Kaur J, Kaur M, Sachdeva M, Kaur N, Duggal N. Comparison of two different types of techniques for obturation of endodontic canals using gutta percha. International Journal of Research in Health and Allied Sciences 2019;5(5):118-121.

35. S P Behera S, Soumya S, Agarwal P, Patri G, Kumar M. Obturation an Overview. IP Indian J Conserv Endod. 2021;6(1):11-20.

36. Al-Dewani N, Hayes SJ, Dummer PMH. Evaluation of the Trifecta obturating technique. Dent Traumatol. 2000;16(2):75-83.

37. Goldberg F, Massone EJ, Artaza LP. Comparison of the sealing capacity of three endodontic filling techniques. J Endod. 1995;21(1):1-3.

38. Inan $U$, Aydemir $H$, Tasdemir $T$. Leakage evaluation of three different root canal obturation techniques using electrochemical evaluation and dye penetration evaluation methods. Aust Endod J. 2007;33(1):18-22.

39. Farea M, Masudi S, Bakar WZW. Apical microleakage evaluation of system $B$ compared with cold lateral technique: In vitro study. Aust Endod J. 2010;36(2):48-53.

40. Dds CS, Smart CJ. VCU Scholars Compass Microbial Evaluation of the Calamus Heated GuttaPercha Delivery System. 2013; 1-27

41. Mozo S, Llena C, Forner L. Review of ultrasonic irrigation in endodontics: increasing action of irrigating solutions. Med Oral Patol Oral Cir Bucal 2012;17(3):512-518.

42. Sluis L Van Der. Ultrasound in endodontics. Endo 2007;1(1):29-36.

43. Townsend C, Maki J. An In Vitro Comparison of New Irrigation and Agitation Techniques to Ultrasonic Agitation in Removing Bacteria From a Simulated Root Canal. J Endod 2009;35(7):1040-1043.

44.Lyudmila Y. Orekhova, Tat'yana V. Porkhun, Veronika Y. Vashneva, Ekaterina A. Rubezhova. Application of ultrasound in endodontics. Стоматолог 2017;3:21-26. 